\title{
Word from the Editors and conference organisers
}

\author{
Jean-Michel Beacco $^{1} \cdot$ Marielle de Jong $^{2} \cdot$ Dan diBartolomeo $^{3} \cdot$ André Lévy-Lang $^{1}$
}

(C) Springer Nature Limited 2018

Six months after the Financial Risks International Forum took place in Paris for the 11th consecutive year, we are pleased to publish this special issue dedicated to the research that was presented there. We feel that the selection of articles it features gives a good idea of the spirit of the conference and the impetus it gave to the attendees. The purpose of the issue is to leave a record of the serious research efforts that were made, and of the topics that were discussed. We are most thankful to the contributors for their kind cooperation and for sharing their outstanding work.

The central theme of the conference was to look at the roles the capital markets play, or could play, which go beyond their primary function of funding the economy. There is more at stake than an efficient exchange of capital, and we see the investment community becoming increasingly aware of that. There are considerations that rightly go beyond the elementary financial prospects of an investment matter. Extra-financial issues matter because they imply tangible risks that may have serious financial consequences for the invested capital. At the Forum, attention was paid to a series of extra-financial issues, such as climate change, or more generally, a shift in focus from shareholder-towards stakeholder values, the stability of the financial system itself and uncharted demographic developments.

The conference speakers agreed to say that most of these risks are latent, in the sense that they may give rise to new

Marielle de Jong

marielle.dejong@amundi.com

Louis Bachelier Institute, Paris, France

Amundi, Paris, France

3 Northfield Information Service, Boston, USA situations in which the outcome of a capital investment may be unfavourable. It is not evident how to assess such risks. The first key hurdle is to actually identify the sources of risk and to hypothesise how, if no corrective action is taken, they may lead to unfavourable events. What is even harder is to test the hypotheses that are made upon real market data. Tests on historical prices of traded assets will likely fail to give confirmation of latent risk sources. This situation may change though as soon as market participants start to feel concerned about the newly emerging risks and adjust their investment decisions accordingly. In that event, prices may start to move long before the risks are realised.

Here, we believe, lies a role to play for the capital markets. Due to the forward-looking nature of trade prices, latent risks are liable to become real in financial terms at the instant they are recognised to exist by market participants. The pricing pressure this evokes may go two ways: either the prices of the securities that are impacted by the potentially risky event, adjust downwards towards a lower equilibrium level, or the issuers of these securities try to avoid this price drop and decide to take corrective action. If they do so the eventual unfavourable event that causes the concern may be avoided. It may even be that the price adjustment in the anticipation of the unfavourable event is avoided. That would be a win for all parties involved. This is an important role for the markets to perform to which we feel research attention should be given.

Much work remains to be done. In the first place, there is a call for new data sources which can make the impact of extra-financial issues on invested capital measurable. To take an example, the extent to which companies pollute or to what extent their products are vulnerable to changing weather circumstances are becoming relevant pieces of information in the objective to assess the longer-term risk profiles of the assets issued by these companies. 
Interestingly, credit rating agencies are in effect starting to integrate these pieces of information into their rating models, and that move is a concrete step towards a real pricing of climate matters. In the second place, there is a call for new financial instruments that take account of extra-financial issues. Through these instruments, risks can be transferred from the bearers towards an investment community broad enough to induct pricing pressure. The Green Bond is an example of such new instrument, which was created about a decade ago to finance climate-friendly business projects.

There is a third call that is vital for the capital markets to pick up new roles and for the newly-designed instruments to thrive, which is the legal setup of the market. Blueprints need to be drafted stipulating how the markets should function so that trades will be efficient and equitable. It requires directives and commitment from governments and international authorities. To pick up the example of the Green Bond again, such bond cannot get started and become truly operational without an official certifying label. The World Bank is instrumental in establishing one, notably by drawing up the Green Bond Principles (GBP) in 2014: "The GBP are intended for broad use by the market: they provide issuers guidance on the key components involved in launching a credible Green Bond; they aid investors by ensuring availability of information necessary to evaluate the environmental impact of their Green Bond investments; and they assist underwriters by moving the market towards standard disclosures which will facilitate transactions." Only if all parties adhere and are confined to these principles can the Green Bond market truly take off.

We are privileged to have the participation of keynote speaker Professor David Blake who shares his thoughts, in the lead-off Editorial, on an interesting area of market innovation, namely on the Life Market that he has helped create in the UK about a decade ago. On the Life Market, new assets are traded that are linked to longevity risk, i.e., unanticipated changes in life expectancy. This market has two segments: a macrosegment with assets linked to groups of lives, such as members of a pension plan or a book of annuitants; and it has a microsegment with assets linked to individual lives, such as life settlements. Longevity is a major concern for pension funds, and ultimately for governments, as longer life may be a good thing for mankind, it does represent, if not well accommodated, a looming financial liability. David describes how the Life Market can be a means in resolving that.

David has given and continues to give valuable input in drawing the blueprints for the Life Market, in particular by designing new financial instruments that can be exchanged between parties. He co-designed the so-called survivor bonds back in 2001 as well as the survivor swaps in 2006, which eventually gave rise to the bulk annuity transactions that are being exchanged today; there are as it stands three types of instruments, the buy-outs, buy-ins and the longevity swaps. The interest of these instruments is that they make the transfer of longevity risk possible, relieving the principal bearers of risk, the pension funds, and in the same time creating new investment opportunity for a broader set of market players who are looking out for new sources of return and diversification.

The Life Market, or the Longevity Risk Transfer Market as the Bank of International Settlements has coined it, is still in its early days. For this market to develop further and play a prominent role on a global scale, certain elementary market requirements are yet to be satisfied, David argues, such as the development of market indices linked to national population mortality and reliable mortality forecasting models. Governments should also become more proactive in stimulating such developments: they certainly have an interest to do so, since an effective Life Market could help to reduce the burdens that will otherwise fall in future generations. If the causal factors underlying longevity were better understood and appreciated, longevity risk can be better shared, more sharply priced and will consequently be better assessed, which is beneficial for all parties. That is exactly the role of the Life Market, to bring a more efficient assessment and pricing of longevity risk, so that pensioners will be better served and eventually governments relieved from the latent liability.

Following the Editorial, the first article entitled "Managing the Financial Consequences of Weather Variability" by Jean-Louis Bertrand and Xavier Brusset, is an early result in a relatively new research area. In their article, they investigate whether a link can be made between weather variability and economic activity. This question is becoming pressing now that scientists have given confirmation that (1) the weather is indeed becoming more variable and (2) this is a direct consequence of global warming. The authors actually find a measurable impact of the change in weather patterns in the sales of sunscreen products. The interest of the paper lies there, in making that link. It is a first step towards building tractable means of assessing investment risks that are related to the weather, and more remotely to the looming global warming.

Among the actors on the market those working in the insurance industry are particularly vocal in raising the alarm. Their motives are clear: "I know how to insure a world that heats up at most two degrees a century, beyond that I am not sure" was the statement made by a senior director in the industry a few years ago. Insurance companies are becoming seriously engaged in undertaking projects that aim to curb global warming. At the conference, a special session was dedicated to the question how to insure extreme risks. The role of CAT (catastrophe) bonds was substantially discussed which insure the holders 
against financial losses that occur in the event of a natural catastrophe.

In the second article entitled "Corporate Ownership Structure, Market Anomalies and Asset Pricing," Souad Lajili Jarjir and Marc Desban raise an elementary question concerning new or latent risk sources, namely how to identify them and how to fit them into the standing asset pricing models that typically ignore their existence. Souad and Marc make investigations in a specific domain, namely they study whether the structure of corporate ownership has a notable incidence on asset prices. It is an interesting question that is not much addressed in the finance literature. The authors choose to undertake this study on the French equity market, which is known to stand out for its insider system in terms of corporate ownership.

They indeed find pricing anomalies with respect to a standard capital asset pricing model that can be attributed to the specific ownership structure. They consequently adapt the model so as to fit the French context. "Reliable asset pricing models are needed to be able to estimate the cost of capital, calculate abnormal returns and reallocate the portfolios accordingly," they argue, "Investors operating on the markets need reliable asset pricing models. Understanding why asset pricing models fail to explain stock returns can help investors to adjust their investment decisions."

Their research contributes to the efforts made to integrate latent risks related to extra-financial topics into the standard market mechanisms. The world seems to be moving away from an era of shareholder value, whereby the financers of corporate activity were primarily served, towards a new era of so-called stakeholder value where a broader group of bystanders are being served as well. The seminal question from an investment point of view is how this effect impacts asset prices. If stakeholder value is to become the norm and companies will be held responsible for all acts that have consequences for third parties, the market valuation of the assets they issue will inevitably adjust. The topic of the article is to extend the standing asset pricing models and challenge the academic community about new issues related to financial and extra-financial dimensions.

The gradual but seemingly inevitable shifts that we are facing, such as climate change, the making of the stakeholder society and the ageing population, are leading the investment world into unchartered territory, where new paradigms apply. New paradigms call for new assessment methods, and as long as these are not fully developed, the investor may be at a loss. The importance of that is not to be underestimated. If investors start to feel incapable of assessing the financial outcomes of investments within

reason, they will become reluctant to invest at all, or in the least, make capital protection their priority. Such attitude will, if it becomes widespread, by itself have an impact on asset prices, regardless of the particular risk issues that are at stake.

The notion of uncertainty is not be confused with risk aversion. Uncertainty goes beyond the usual trade-off that investors make between extra gain versus extra risk depending on their aversion and appetite. Uncertainty arises when it becomes impossible to identify and assess risks. In that situation investors will disinvest or, if that is not an option, they will seek to diversify their portfolio in an attempt to protect their capital. At the conference, a special session was dedicated to the question of uncertainty, that led to interesting discussions. The apprehension for a surge in uncertainty among investors in the time to come makes us reiterate the importance of paying attention to the new fields of research.

In the midst of the discussions speculating about which threats are to come that could weaken the financial system, one conference session was dedicated to risks that may come from within. More specifically, the behaviour of investors operating on the markets may in certain circumstances have an influence on trade prices, and by that induce risk. Senior economist Richard Thaler received the Nobel Prize last year for the research he has done in this field. The last two articles in this special issue concentrate on this question: "A Critique of Momentum Strategies" by Yang Gao, Henry Leung and Stephen Satchell, and "Keep Up the Momentum" by Thierry Roncalli. Interestingly, in both articles, a price impact is detected that is related to investor behaviour which is distinctly different when the market is bearish or bullish. It is good to realise when entering the market that bears don't behave like bulls!

We are most grateful to the conference organisers Marie Brière and Christian Gouriéroux for all efforts and kind cooperation.

Jean-Michel Beacco and André Lévy-Lang

General Director and President, respectively, of the Louis

Bachelier Institute
Marielle de Jong and Dan diBartolomeo

Editors 